\title{
Affective Correlates of Stimulant Use and Adherence to Anti-retroviral Therapy Among HIV-positive Methamphetamine Users
}

\author{
Adam W. Carrico $\cdot$ Mallory O. Johnson • \\ Grant N. Colfax $\cdot$ Judith Tedlie Moskowitz
}

Published online: 6 January 2009

(c) The Author(s) 2008. This article is published with open access at Springerlink.com

\begin{abstract}
The use of stimulants has important implications for HIV prevention and care. However, few investigations have examined psychological correlates of substance use and adherence to anti-retroviral therapy (ART) among HIV-positive stimulant users. This crosssectional investigation examined affective correlates of stimulant use and ART adherence among HIV-positive methamphetamine users. In total, 122 HIV-positive men who have sex with men or transgendered individuals on ART who reported using methamphetamine in the past 30 days were recruited from the community. HIV-specific traumatic stress was consistently and independently associated with more frequent cocaine/crack use (but not with methamphetamine use). Positive affect was independently associated with a decreased likelihood of reporting any injection drug use and an increased likelihood of reporting perfect ART adherence. HIV-specific traumatic stress may be an important determinant of increased cocaine/crack use in this population. Positive affect may increase the
\end{abstract}

\author{
A. W. Carrico $(\varangle) \cdot$ M. O. Johnson \\ Center for AIDS Prevention Studies, University of California, \\ San Francisco, 50 Beale St., Suite 1300, San Francisco, \\ CA 94105, USA \\ e-mail: adam.carrico@ucsf.edu \\ G. N. Colfax \\ San Francisco Department of Public Health, AIDS Office, \\ San Francisco, CA, USA \\ G. N. Colfax \\ Positive Health Program, San Francisco General Hospital, \\ San Francisco, CA, USA \\ J. T. Moskowitz \\ Osher Center for Integrative Medicine, University of California, \\ San Francisco, CA, USA
}

likelihood that individuals will refrain from injection drug use and achieve high levels of ART adherence.

Keywords Cocaine - HIV/AIDS - Methamphetamine . Positive affect $\cdot$ Trauma $\cdot$ Self medication hypothesis

\section{Introduction}

Stimulant use is associated with increased rates of HIV transmission risk behavior, acquisition of strains of HIV that are resistant to some classes of antiretroviral medications, impaired adherence to anti-retroviral therapy (ART), and elevated HIV viral load (Carrico et al. 2007; Colfax et al. 2007; Gorbach et al. 2008; Hinkin et al. 2007; Johnson et al. 2008; Morin et al. 2007). Consequently, stimulant users have been identified as an important group to target for HIV prevention efforts. There is some preliminary evidence that behavioral interventions designed to enhance motivation as well as bolster self-efficacy for reducing sexual risk taking are effective in decreasing HIV transmission risk behavior in methamphetamine users (Mausbach et al. 2007). However, little is known about the role of potentially modifiable psychological factors (like affective states) in relation to substance use and ART adherence among HIV-positive stimulant users. In a prior cross-sectional investigation, we observed that enhanced affect regulation was indirectly associated with lower HIV viral load via two independent behavioral pathways, a decreased likelihood of reporting regular stimulant use and better self-reported ART adherence (Carrico et al. 2007). Although these findings are informative, further investigations are needed to examine specific affective correlates of these important health behaviors in HIV-positive stimulant users. 
HIV-specific Traumatic Stress and Negative Affect

There is increasing recognition that individuals may experience HIV-specific traumatic stress, symptoms of posttraumatic stress disorder (PTSD) that stem from the experience of living with HIV/AIDS (Delahanty et al. 2004; Semple et al. 2002). HIV-specific traumatic stress and negative affect may have important implications for selfregulation of a variety of behaviors, including substance use.

Consistent with the self medication hypothesis (Khantzian 1997), emerging empirical evidence from clinical investigations indicates that one core feature of substance use disorders appears to be difficulties with awareness or tolerance of internal experiences that can serve as triggers for continued substance use (Carrico et al. 2007; Gifford et al. 2006; Hayes et al. 1996; Morgenstern et al. 1997; O'Cleirigh et al. 2007). This is further supported by the results of one qualitative investigation where HIVpositive methamphetamine users on ART reported that using methamphetamine provided a temporary respite from intrusive thoughts (an important PTSD symptom) about their HIV serostatus (Semple et al. 2002). Although substance use may allow individuals to avoid intrusive thoughts or negative mood states in the short-term, increases in depressive symptoms are commonly observed over time (Kosten et al. 1998). Elevated depressive symptoms, in turn, predict continued substance use as well as relapse to substance use across a variety of populations (Baker 2006; Baker et al. 2004). Taken together, results of these investigations indicate that HIV-specific traumatic stress and negative affect may be important triggers for stimulant use.

Other investigations have examined the extent to which negative affect and PTSD symptoms may impair the capacity of individuals to effectively adhere to ART regimens. There is burgeoning evidence that depressive symptoms and other forms of negative affect are directly or indirectly associated with ART non-adherence (Johnson et al. 2003; Starace et al. 2002; Weaver et al. 2005). However, investigations examining whether PTSD symptoms are independently related to ART non-adherence have obtained mixed results (Delahanty et al. 2004; Sledjeski et al. 2005; Vranceanu et al. 2008). Delahanty et al. (2004) observed that HIV-specific traumatic stress was associated with poorer ART adherence, but also with lower salivaryfree cortisol in the 30-45 min after awakening and higher CD4+ cell counts. In contrast to these findings, other studies have observed that HIV-specific traumatic stress as well as general PTSD symptoms from any trauma (including HIV) are not independently related to lower ART adherence after accounting for depressive symptoms (Sledjeski et al. 2005; Vranceanu et al. 2008). These discrepant findings highlight the need for further investigations to determine if negative affect and HIV-specific traumatic stress are independently associated with poorer ART adherence.

\section{Positive Affect}

Positive affect can occur with relatively high frequency in the midst of a chronic stressor such as living with HIV, and investigations informed by stress and coping theory have observed that it serves important adaptive functions (Folkman 2008; Folkman and Moskowitz 2000). In contrast to the narrowing of attention and specific action tendencies that occurs with the experience of negative affect, positive affect broadens an individual's attention focus and behavioral repertoire (Fredrickson and Branigan 2005). Experimental evidence also indicates that inducing positive emotions after a stressful laboratory task promotes enhanced self-regulation (Tice et al. 2007). These beneficial cognitive and behavioral effects of positive affect may have important implications for substance use and ART adherence.

Individuals may use stimulants to enhance positive affect in the short-term. Over time, however, substance use can erode numerous psychosocial resources, increasing reliance of substance use as way of coping (Witkiewitz and Marlatt 2004). Positive affect may reinvigorate cognitive-behavioral coping efforts that are crucial to decrease reliance on substance use as a means of affect regulation (Wills et al. 1999). In addition, positive affect assists individuals with building psychosocial resources that promote resilience in the face of chronic stress (Fredrickson 2001; Fredrickson et al. 2003), potentially decreasing the likelihood of continued substance use or relapse to substance use. Investigations are needed to examine whether positive affect is independently associated with decreased stimulant use.

The vast majority of investigations examining psychological correlates of adherence to medical regimens have focused on various forms of negative affect and PTSD symptoms. In fact, to our knowledge no investigation to date has examined the potential role of positive affect in promoting ART adherence. One study that excluded individuals with substance dependence observed that the association between perceived social support and improved ART adherence was mediated by increased positive states of mind (Gonzalez et al. 2004). In another study, Littlewood et al. (2008) observed that the extent to which individuals were able to find benefits in living with HIV/AIDS was associated with improved psychological adjustment and increased physical activity, but it was unrelated to ART adherence, alcohol use, or cigarette smoking. It may be that discrepant findings are partially due to the fact that measures of these positive psychological resources do not directly assess positive affect, which may be a more robust correlate of ART adherence and other health behaviors. 


\section{Current Study}

The primary goal of the present investigation was to examine the extent to which HIV-specific traumatic stress, negative affect, and positive affect are independently associated with stimulant use and ART adherence among HIV-positive methamphetamine users. Specifically, we hypothesized that: (1) HIV-specific traumatic stress and negative affect would be independently associated with greater stimulant use and impaired ART adherence; and (2) positive affect would be independently associated with less stimulant use and better ART adherence.

\section{Methods}

\section{Procedures}

To be eligible for participation in the present study, individuals were required to: (1) be 18 years or older; (2) speak English; (3) self-identify as man who has sex with men (MSM) or as transgendered; (4) provide evidence of a current prescription for an ART regimen; (5) have been taking an ART regimen for at least 1 month; and (6) report using methamphetamine during the past 30 days. Participants were recruited from medical clinics, pharmacies, community-based organizations that serve HIV-positive persons, outpatient mental health and substance abuse treatment programs, other studies for HIV-positive persons, bars/clubs, and through street outreach. Of the 272 individuals who completed a brief telephone screen, 132 (49\%) were determined to be eligible. Of these, 122 (92\%) completed a study visit. All measures were administered to participants in a face-to-face interview format and individuals were reimbursed for their time with a $\$ 30$ gift card to a local grocery store. Study procedures were approved by the University of California, San Francisco Committee on Human Research.

\section{Measures}

\section{Demographics and Health Status}

Age, ethnicity, gender, sexual orientation, education, income, relationship status, time since HIV diagnosis, time since starting ART, self-reported CD4+ count, and selfreported detectable HIV viral load were assessed by questionnaire.

\section{Affect}

Positive and negative affect schedule (PANAS). The intensity of positive and negative affect during the past week was assessed using the 20-item PANAS (Watson et al. 1988). The PANAS was designed to assess two relatively independent constructs: high activation positive affect (e.g., interested, excited) and high activation negative affect (e.g., upset, ashamed). The positive (Cronbach's $\alpha=.92$ ) and negative (Cronbach's $\alpha=.89$ ) affect subscales of the PANAS demonstrated good internal consistency.

Impact of event scale (IES). The 15-item IES assesses how frequently individuals experienced symptoms of intrusive thoughts (e.g., I thought about it when I didn't mean to) as well as avoidance of triggers for intrusive thoughts (e.g., I tried to remove it from memory) during the past week with regard to a specific event. This measure has been consistently associated with symptoms of PTSD, anxiety, and depression (Sundin and Horowitz 2002, 2003). In order to assess HIVspecific traumatic stress, participants rated how frequently they experienced intrusive thoughts and avoidance with respect to HIV/AIDS. The IES composite score demonstrated good internal consistency (Cronbach's $\alpha=.91$ ). As shown in Table 1, HIV-specific traumatic stress was in the moderate range (Sundin and Horowitz 2003).

\section{Substance Use}

Frequency of stimulant use. Participants reported the number of days during the past month that they used cocaine, crack, and methamphetamine. Data were dichotomized to examine individuals who used these substances at least weekly on average because weekly stimulant use is independently associated with elevated HIV viral load and immune activation in ART-treated HIV-positive persons (Carrico et al. 2008). Participants who reported using for 4 or more days during the past month were compared to those who reported using 0-3 days. Because methamphetamine use was part of the inclusion criteria, it was examined separately.

Binge stimulant use. Participants rated the longest number of consecutive days that they used cocaine, crack, and methamphetamine during the past month. Participants who reported using 2 or more days in a row during the past month were compared to those who reported no consecutive days of use. Because methamphetamine use was part of the inclusion criteria, it was examined separately.

Recent stimulant use. In total, 114 participants provided a urine sample for on-site toxicology screening using a Redicup $^{\circledR}$ test kit (Redwood Toxicology Laboratory, Inc.). This kit is designed to test for the presence of metabolites $($ Tox +$)$ that are indicative of recent use of methamphetamine (D-Amphetamine $\geq 1,000 \mathrm{ng} / \mathrm{ml}$ ) and cocaine (Benzoylecgonine $\geq 300 \mathrm{ng} / \mathrm{ml}$ ).

Injection drug use. Participants reported the number of days that they injected substances during the past month. Those who reported any injection drug use were compared to participants who denied injection drug use. 
Table 1 Demographic and clinical characteristics of 122 HIV-positive individuals on ART (San Francisco, 2007-2008)

\begin{tabular}{|c|c|}
\hline Variable & $n(\%)$ \\
\hline \multicolumn{2}{|l|}{ Gender } \\
\hline Male & $115(94)$ \\
\hline Transgender (male to female) & $5(4)$ \\
\hline Transgender (female to male) & $2(2)$ \\
\hline \multicolumn{2}{|l|}{ Sexual orientation } \\
\hline Exclusively heterosexual & $3(3)$ \\
\hline Predominantly heterosexual & $6(5)$ \\
\hline Bisexual & $15(12)$ \\
\hline Predominantly gay & $20(16)$ \\
\hline Exclusively gay & $78(64)$ \\
\hline \multicolumn{2}{|l|}{ Ethnicity } \\
\hline African American & $39(32)$ \\
\hline Hispanic/Latino & $17(14)$ \\
\hline Asian/Pacific Islander & $2(2)$ \\
\hline Native American/Alaskan Native & $2(2)$ \\
\hline Caucasian & $50(41)$ \\
\hline Multi-cultural & $12(9)$ \\
\hline \multicolumn{2}{|l|}{ Education } \\
\hline Did not graduate high school & $17(14)$ \\
\hline High school graduate & $31(26)$ \\
\hline Some college & $42(34)$ \\
\hline College graduate or greater & $32(26)$ \\
\hline \multicolumn{2}{|l|}{ Income } \\
\hline$<\$ 5,000$ & $11(9)$ \\
\hline$\$ 5,000-\$ 11,999$ & $54(44)$ \\
\hline$\$ 12,000-\$ 15,999$ & $26(21)$ \\
\hline$\$ 16,000-\$ 24,999$ & $20(17)$ \\
\hline$\$ 25,000-\$ 74,999$ & $11(9)$ \\
\hline Currently in a primary relationship & $48(39)$ \\
\hline \multirow[t]{2}{*}{ Undetectable HIV viral load (self report) } & $74(61)$ \\
\hline & $M(\mathrm{SD})$ \\
\hline Age & $44(6)$ \\
\hline Time since HIV diagnosis (in years) & $14(6)$ \\
\hline Time since starting ART (in years) & $8(6)$ \\
\hline CD4+ count (self report) & $486(603)$ \\
\hline Positive affect (PANAS) ${ }^{\mathrm{a}}$ & $33.0(8.5)$ \\
\hline Negative affect (PANAS) ${ }^{\mathrm{a}}$ & $22.5(8.4)$ \\
\hline HIV-specific traumatic stress $\left(\right.$ IES) ${ }^{\mathrm{b}}$ & $25.6(18.4)$ \\
\hline
\end{tabular}

a Possible range of scores was 10-50

b Possible range of scores was 0-75

\section{ART Adherence}

Self-report measures of ART adherence are often correlated with adherence estimates using more direct measures (e.g., electronic medication cap monitoring) and selfreported adherence is generally associated with HIV viral load (Simoni et al. 2006). The present investigation utilized the visual analogue scale, a self-report measure of ART adherence that has been strongly correlated with unannounced pill counts and moderately correlated with HIV viral load (Giordano et al. 2004; Oyugi et al. 2004). Because self-report measures are thought to overestimate adherence, we compared participants who reported being $100 \%$ adherent to their ART regimen to those who reported missing at least one dose of medication during the past month.

\section{Statistical Analyses}

The present investigation utilized binary logistic regression to examine correlates of substance use and ART adherence. Because previous investigations have observed that demographic characteristics such as age and ethnicity may be important correlates of stimulant use and ART adherence (Gordillo et al. 1999; Grov et al. 2006; Halkitis and Jerome 2008; Halkitis et al. 2008), we examined the effects of affective states after controlling for these factors. In the model examining ART adherence, time since HIV diagnosis and time since starting ART were entered as additional covariates. HIV-specific traumatic stress, negative affect, and positive affect were entered simultaneously in the second regression block in order to obtain an adjusted odds ratio (AOR). This AOR reflects the independent effects of each after adjusting for covariates in the first block. With the exception of age, all continuous predictors were transformed into $z$-scores $(M=0, \mathrm{SD}= \pm 1)$ to facilitate interpretation of the AOR. Because the majority of participants were MSM, we conducted separate analyses to confirm that results were similar after excluding transgendered participants.

\section{Results \\ Participant Characteristics}

As shown in Table 1, the mean age of participants was 44 (range 26-51). The majority of participants were MSM (94\%). Among the MSM, $84 \%$ identified as predominantly or exclusively gay. The sample was relatively diverse with respect to ethnicity: $41 \%$ Caucasian, 32\% African American, 14\% Hispanic/Latino, 2\% Asian/Pacific Islander, 2\% Native American/Alaskan Native, and 9\% of multi-cultural heritage. Most participants $(60 \%)$ had completed at least some college and the modal income was $\$ 5,000-\$ 11,999 /$ year. Individuals had been diagnosed with HIV for an average for 14 years (range 2-27) and had been taking ART for 8 years (range .25-20) on average. The mean selfreported CD4+ count was 486 cells $/ \mathrm{mm}^{3}$ and most 
participants $(61 \%)$ reported having an undetectable HIV viral load.

\section{Preliminary Analyses}

Because individuals often use multiple stimulants, we began by examining the associations between indices of methamphetamine and cocaine/crack use. Use of cocaine/ crack at least weekly was not associated with using methamphetamine at least weekly $(\mathrm{OR}=.55, P>.05$; $95 \% \mathrm{CI}=.26-1.18)$. Binge use of cocaine or crack was also not associated with binge use of methamphetamine $(\mathrm{OR}=.51, \quad P>.05 ; 95 \% \quad \mathrm{CI}=.24-1.11)$. However, individuals who were Tox + for cocaine/crack were significantly less likely to be Tox + for methamphetamine $(\mathrm{OR}=.30, P<.05 ; 95 \% \mathrm{CI}=.12-.76)$.

Next, in order to establish the validity of our selfreported measure of adherence, we examined correlations with measures of self-reported immune status that have previously been demonstrated to be reliable and valid indicators of actual values (Kalichman et al. 2000). Using Spearman correlations, reporting 100\% ART adherence during the past month was associated with higher selfreported $\mathrm{CD} 4+$ count $(r=.22, P<.05)$ and marginally associated with a decreased likelihood of reporting a detectable HIV viral load $(r=-.18, P=.054)$.

\section{Correlates Methamphetamine Use}

During the past month, $53 \%$ of participants reported using methamphetamine at least weekly and $63 \%$ reported binge use of methamphetamine. Approximately 32\% of participants were Tox + for methamphetamine at their study visit. Compared to Caucasian participants, African American individuals were significantly less likely to report use of methamphetamine at least weekly $(\mathrm{AOR}=.15, P=.01)$ and less likely to report binge use of methamphetamine (AOR $=.10, P<.01)$. African American participants were also marginally less likely to be Tox + for methamphetamine at their study visit $(\mathrm{AOR}=.37, P=.06)$. Compared to Caucasians, Hispanic/Latino participants were less likely to report binge use of methamphetamine $(\mathrm{AOR}=.20, P<.05)$ and were less likely to be Tox + for methamphetamine at their study visit $(\mathrm{AOR}=.12$, $P<.05)$. Elevated negative affect was independently associated with a greater likelihood of reporting methamphetamine use at least weekly $(\mathrm{AOR}=1.76, P<.05)$, but was not significantly related to reporting binge use or being Tox + for methamphetamine. Elevated HIV-specific traumatic stress was independently associated with a decreased likelihood of being Tox + for methamphetamine (AOR $=.52, P<.05)$, but was unrelated to indices of selfreported methamphetamine use. Results of these logistic regression analyses are summarized in Table 2. Findings were comparable when only data from MSM were examined.

\section{Correlates of Cocaine/Crack Use}

During the past month, 33\% of participants reported using cocaine/crack at least weekly and $33 \%$ reported binge use of cocaine/crack. Approximately $37 \%$ of participants were Tox + for cocaine/crack at their study visit. Compared to Caucasian participants, African American individuals were significantly more likely to report cocaine/crack use at least weekly $(\mathrm{AOR}=3.66, P<.05)$, report binge use of cocaine/crack $(\mathrm{AOR}=2.93, P<.05)$, and be Tox + for cocaine/crack $(\mathrm{AOR}=5.19, P<.01)$. In addition, elevated HIV-specific traumatic stress was independently associated with a greater likelihood of reporting cocaine/

Table 2 Logistic regression analyses for indices of methamphetamine use

\begin{tabular}{|c|c|c|c|c|c|c|}
\hline \multirow[t]{2}{*}{ Predictor variable } & \multicolumn{2}{|c|}{ At least weekly } & \multicolumn{2}{|c|}{ Binge use } & \multicolumn{2}{|c|}{ Tox + urine screen } \\
\hline & AOR & $95 \% \mathrm{CI}$ & AOR & $95 \% \mathrm{CI}$ & AOR & $95 \% \mathrm{CI}$ \\
\hline Age & .95 & $.89-1.01$ & .93 & $.87-1.00$ & .95 & $.89-1.01$ \\
\hline Caucasian & 1.00 & Reference & 1.00 & Reference & 1.00 & Reference \\
\hline African American & $.15^{* *}$ & $.06-.41$ & $.10 * *$ & $.03-.29$ & .37 & $.13-1.04$ \\
\hline Hispanic/Latino & .39 & $.12-1.33$ & $.20 *$ & $.05-.78$ & $.12 *$ & $.02-.64$ \\
\hline Other ethnic minority & .64 & $.19-2.19$ & .47 & $.11-1.98$ & .37 & $.09-1.46$ \\
\hline Positive affect (PANAS) & 1.21 & $.74-1.98$ & .98 & $.58-1.64$ & 1.00 & $.57-1.75$ \\
\hline Negative affect (PANAS) & $1.76^{*}$ & $1.02-3.03$ & 1.54 & $.86-2.75$ & 1.60 & $.93-2.78$ \\
\hline HIV-specific traumatic stress (IES) & .73 & $.46-1.15$ & .75 & $.46-1.22$ & $.52 *$ & $.30-.90$ \\
\hline
\end{tabular}

Analyses included all available data from the 122 participants

$A O R$ adjusted odds ratio

$* P<.05 ; * * P \leq .01$ 
crack use at least weekly $(\mathrm{AOR}=2.18, P<.01)$, reporting binge use of cocaine/crack $(\mathrm{AOR}=1.86, P<.01)$, and being Tox + for cocaine/crack $(\mathrm{AOR}=1.74, P<.05)$. Results of these logistic regression analyses are summarized in Table 3. Findings were comparable when only data from MSM were examined.

\section{Correlates of Injection Drug Use and ART Adherence}

Approximately $44 \%$ of participants reported injection drug use in the past month, and of these the vast majority (85\%) reported that they had injected only methamphetamine. Elevated positive affect was independently associated with a decreased likelihood of reporting injection drug use during the past month (AOR $=.62, P<.05)$. For ART adherence, $\sim 26 \%$ of participants reported taking every medication dose in the past month. Higher positive affect was independently associated with increased likelihood of reporting perfect ART adherence during the past month $(\mathrm{AOR}=1.79, P<.05)$. We also replicated findings for
ART adherence in a secondary analysis using a less stringent cut-off. Positive affect was marginally associated with an higher odds of reporting ART adherence that was greater than or equal to $90 \%$ in the past month (AOR $=1.63, P=.051 ; 95 \% \mathrm{CI}=1.00-2.65)$. Results of logistic regression analyses examining injection drug use and 100\% ART adherence are summarized in Table 4. Findings were comparable when only data from MSM were examined.

\section{Discussion}

The present investigation provides empirical support for the self medication hypothesis (Khantzian 1997), which posits that difficulties with affect regulation are a key determinant of substance abuse. We observed that HIVspecific traumatic stress was independently associated with increased likelihood of reporting at least weekly use as well as binge use of cocaine/crack. In addition, when examining

Table 3 Logistic regression analyses for indices of cocaine/crack use

\begin{tabular}{|c|c|c|c|c|c|c|}
\hline \multirow[t]{2}{*}{ Predictor variable } & \multicolumn{2}{|c|}{ At least weekly } & \multicolumn{2}{|c|}{ Binge use } & \multicolumn{2}{|c|}{ Tox + urine screen } \\
\hline & AOR & $95 \% \mathrm{CI}$ & AOR & $95 \% \mathrm{CI}$ & AOR & $95 \% \mathrm{CI}$ \\
\hline Age & 1.06 & $.99-1.13$ & 1.06 & $.99-1.13$ & 1.05 & $.98-1.13$ \\
\hline Caucasian & 1.00 & Reference & 1.00 & Reference & 1.00 & Reference \\
\hline African American & $3.66^{*}$ & $1.31-10.23$ & $2.93 *$ & $1.08-7.96$ & $5.19 * *$ & $1.81-14.87$ \\
\hline Hispanic/Latino & 1.77 & $.43-7.29$ & 2.21 & $.58-8.42$ & 2.37 & $.60-9.42$ \\
\hline Other ethnic minority & 3.06 & $.79-11.77$ & 1.93 & $.50-7.36$ & 2.67 & $.66-10.79$ \\
\hline Positive affect (PANAS) & .78 & $.47-1.29$ & .79 & $.48-1.30$ & .79 & $.48-1.31$ \\
\hline Negative affect (PANAS) & .77 & $.45-1.33$ & .85 & $.51-1.44$ & .87 & $.51-1.47$ \\
\hline HIV-specific traumatic stress (IES) & $2.18 * *$ & $1.33-3.58$ & $1.86^{* *}$ & $1.16-2.99$ & $1.74 *$ & $1.07-2.82$ \\
\hline
\end{tabular}

Analyses included all available data from the 122 participants

$A O R$ adjusted odds ratio

$* P<.05 ; * * P \leq .01$

Table 4 Logistic regression analyses for injection drug use and ART adherence

Analyses included all 122 participants

$A O R$ adjusted odds ratio

$* P<.05$

\begin{tabular}{|c|c|c|c|c|}
\hline \multirow[t]{2}{*}{ Predictor variable } & \multicolumn{2}{|c|}{ Injection drug use } & \multicolumn{2}{|c|}{$100 \%$ ART adherence } \\
\hline & AOR & $95 \% \mathrm{CI}$ & AOR & $95 \% \mathrm{CI}$ \\
\hline Age & 1.01 & $.95-1.07$ & .99 & $.92-1.07$ \\
\hline Caucasian & 1.00 & Reference & 1.00 & Reference \\
\hline African American & .48 & $.19-1.18$ & 1.45 & $.50-4.24$ \\
\hline Hispanic/Latino & .52 & $.16-1.71$ & .90 & $.21-3.77$ \\
\hline Other ethnic minority & .65 & $.20-2.10$ & $4.00^{*}$ & $1.09-14.70$ \\
\hline Time since HIV diagnosis & & & .96 & $.88-1.05$ \\
\hline Time since starting ART & & & 1.06 & $.97-1.17$ \\
\hline Positive affect (PANAS) & $.62^{*}$ & $.38-.99$ & $1.79 *$ & $1.06-3.03$ \\
\hline Negative affect (PANAS) & .89 & $.55-1.43$ & 1.23 & $.71-2.14$ \\
\hline HIV-specific traumatic stress (IES) & .85 & $.55-1.31$ & 1.56 & $.96-2.55$ \\
\hline
\end{tabular}


affective correlates of urine toxicology screening results, an interesting pattern emerged. Although HIV-specific traumatic stress was associated with a decreased likelihood of being Tox + for methamphetamine, this may be partially due to the fact that individuals with elevated HIV-specific traumatic stress were more likely to be Tox + for cocaine at the study visit. Because those with elevated HIV-specific traumatic stress were more likely to have recently used cocaine or crack, this appears to have resulted in artificially lower rates of recent methamphetamine use. This is further supported by the fact that HIV-specific traumatic stress was unrelated to indices of self-reported methamphetamine use during the past month. With regard to other correlates of methamphetamine use, we observed that elevated negative affect was independently associated with at least weekly use but was unrelated to binge use or being Tox + for methamphetamine at the study visit. Because inclusion criteria for the study required that individuals report using methamphetamine at least once in the past month, this selected for a sample that reports more frequent methamphetamine use. The restricted range may have decreased the likelihood of identifying robust affective correlates of methamphetamine use.

Stress and coping theory (Folkman 2008; Folkman and Moskowitz 2000) proposes that positive affect serves important adaptive functions among individuals managing a chronic stressor such as living with HIV, and findings from the present investigation support this theoretical conceptualization. Positive affect was independently associated with a decreased likelihood of engaging in injection drug use during the past month. A previous investigation observed that positive affect may promote cognitive-behavioral coping efforts that assist individuals with decreasing substance use (Wills et al. 1999), and positive affect may also build the capacity of individuals to refrain from engaging in injection drug use. Lending further support to stress and coping theory, we observed that positive affect was independently associated with improved ART adherence. Prior studies have consistently reported that HIV-positive stimulant users are at substantially elevated risk for impaired ART adherence (Carrico et al. 2007; Hinkin et al. 2007; Johnson et al. 2008), but poor ART adherence rates are not universally observed in this population. Positive affect may be an important source of psychological resilience among HIVpositive methamphetamine users that assists individuals with effectively managing difficult ART regimens. Taken together, these data provide some preliminary evidence that positive affect is independently associated with a decreased likelihood of engaging in injection drug use and an increased likelihood of achieving perfect ART adherence among HIVpositive methamphetamine users.

Findings from the present investigation also underscore the importance of attending to ethnic differences in the use of various stimulants among MSM. Previous investigations that recruited MSM at gay-identified venues have reported discrepant findings regarding ethnic differences in substance use (Grov et al. 2006; Halkitis and Jerome 2008; Halkitis et al. 2008). Using large samples of MSM recruited at gay community events in New York City and Los Angeles, Grov et al. (2006) observed that Asian/Pacific Islander men were less likely to report using a variety of substances, but there were no other ethnic differences in substance use. In contrast, other investigations with MSM in New York City have provided some contradictory findings. Although one study observed that African American or Hispanic/Latino participants were more likely to report using methamphetamine (Halkitis et al. 2008), other data suggest that African Americans are significantly less likely to report using methamphetamine compared to Caucasian or Hispanic/Latino participants (Halkitis and Jerome 2008). Results of the present investigation indicate that African American and Hispanic/Latino individuals may be less likely to report methamphetamine use and to be Tox + for methamphetamine. On the other hand, we observed that African Americans were more likely to report using cocaine/crack and were more likely to be Tox + for cocaine at the study visit. Although findings from this convenience sample of HIV-positive methamphetamine users should be interpreted with caution, this highlights that there may be important ethnic differences in the frequency and/or patterns of the use of various stimulants in this population.

Taken together, these data provide some indication that HIV-specific traumatic stress may be an especially important psychological factor that is associated with indicators of more problematic cocaine/crack use among HIV-positive methamphetamine users. However, it is unclear whether elevated HIV-specific traumatic stress reflects the influence of specific HIV-related traumatic stressors (e.g., HIV diagnosis) or if it is more indicative of the cumulative effects of living with this highly stigmatized, chronic illness. This issue should be examined in future studies. Further investigations should also attempt to determine whether HIVspecific traumatic stress is associated with indices of stimulant use after controlling for general PTSD symptoms that stem from other traumatic events that are not related to HIV. It is also noteworthy that the present investigation defined binge use as using stimulants for 2 or more days in a row during the past month. Although even relatively short binges are thought to be related to ART non-adherence and potentially increased sexual risk taking, research with larger samples is needed to more adequately differentiate between binge and chronic stimulant use. Results should also be interpreted with caution given the cross-sectional design and small sample size of the present study. Because we examined affective correlates of stimulant use and ART 
adherence, these data do not provide evidence of a causal relationship. For example, it is plausible that recent substance use may have resulted in exacerbations in HIVspecific traumatic stress and negative affect as well as decreases in positive affect. Difficulties with affect regulation may also be a marker for more severe dependence symptoms, but we were unable to examine this possibility because the present study did not include interview-based methods of diagnosing stimulant abuse or dependence. Despite these limitations, the present study may assist with the development of innovative psychological treatments designed to meet the needs of diverse groups of HIV-positive stimulant users on ART. Specifically, findings highlight that interventions designed to reduce HIV-specific traumatic stress as well as enhance positive affect may be efficacious in decreasing stimulant use and improving ART adherence. Future studies should attempt to replicate these findings with larger samples and examine the clinical relevance of interventions designed to improve affect regulation among HIVpositive stimulant users.

Acknowledgments This research was supported by a health, medicine, and behavior grant from the Anthony Marchionne Foundation. Additional funding for this research was provided by a grant from the National Institute of Mental Health, University of California-San Francisco Center for AIDS Prevention Studies (P30 MH062246-6) and a Ruth L. Kirschstein National Research Service Award (T32MH019391). This project was also supported by Grant Number UL1 RR024131 from the National Center for Research Resources (NCRR), a component of the National Institutes of Health (NIH), and NIH Roadmap for Medical Research, and its contents are solely the responsibility of the authors and do not necessarily represent the official view of NCRR of NIH. Information on NCRR is available at http://www.ncrr.nih.gov/. Information on Re-engineering the Clinical Research Enterprise can be obtained from http://nihroadmap.nih.gov/ clinicalresearch/overview-translational.asp. Finally, the authors would like to thank Kenneth Williams, the research assistant for the present study, who coordinated an excellent recruitment effort and conducted study interviews.

Open Access This article is distributed under the terms of the Creative Commons Attribution Noncommercial License which permits any noncommercial use, distribution, and reproduction in any medium, provided the original author(s) and source are credited.

\section{References}

Baker, T. B. (2006). Pharmacologic and behavioral withdrawal from addictive drugs. Current Directions in Psychological Science, 15(5), 232-236. doi:10.1111/j.1467-8721.2006.00442.x.

Baker, T. B., Piper, M. E., McCarthy, D. E., Majeskie, M. R., \& Fiore, M. C. (2004). Addiction motivation reformulated: An affective processing model of negative reinforcement. Psychological Review, 111(1), 33-51. doi:10.1037/0033-295X.111.1.33.

Carrico, A. W., Gifford, E. V., \& Moos, R. H. (2007a). Spirituality/ religiosity promotes acceptance-based responding and 12-step involvement. Drug and Alcohol Dependence, 89(1), 66-73. doi: 10.1016/j.drugalcdep.2006.12.004.
Carrico, A. W., Johnson, M. O., Moskowitz, J. T., Neilands, T. B., Morin, S. F., Charlebois, E. D., et al. (2007b). Affect regulation, stimulant use, and viral load among HIV-positive persons on anti-retroviral therapy. Psychosomatic Medicine, 69, 785-792. doi:10.1097/PSY.0b013e318157b142.

Carrico, A. W., Johnson, M. O., Morin, S. F., Remien, R. H., Riley, E. D., Hecht, F. M., et al. (2008). Stimulant use is associated with immune activation and depleted tryptophan among HIV-positive persons on anti-retroviral therapy. Brain, Behavior, and Iтmunity, 22, 1257-1262. doi:10.1016/j.bbi.2008.07.010.

Colfax, G. N., Vittinghoff, E., Grant, R., Lum, P., Spotts, G., \& Hecht, F. M. (2007). Frequent methamphetamine use is associated with primary non-nucleoside reverse transcriptase inhibitor resistance. AIDS (London, England), 21(2), 239-241. doi: 10.1097/QAD.0b013e3280114a29.

Delahanty, D. L., Bogart, L. M., \& Figler, J. L. (2004). Posttraumatic stress disorder symptoms, salivary cortisol, medication adherence, and CD4 levels in HIV-positive individuals. AIDS Care, 16(2), 247-260. doi:10.1080/09540120410001641084.

Folkman, S. (2008). The case for positive emotions in the stress process. Anxiety, Stress, and Coping, 21(1), 3-14. doi:10.1080/ 10615800701740457.

Folkman, S., \& Moskowitz, J. T. (2000). Positive affect and the other side of coping. The American Psychologist, 55(6), 647-654. doi: 10.1037/0003-066X.55.6.647.

Fredrickson, B. L. (2001). The role of positive emotions in positive psychology: The broaden-and-build theory of positive emotions. The American Psychologist, 53(3), 218-226. doi:10.1037/0003066X.56.3.218.

Fredrickson, B. L., \& Branigan, C. A. (2005). Positive emotions broaden the scope of attention and thought-action repertoires. Cognition and Emotion, 19, 313-332. doi:10.1080/026999304 41000238.

Fredrickson, B. L., Tugade, M. M., Waugh, C. E., \& Larkin, G. R. (2003). What good are positive emotions in crises? A prospective study of resilience and emotions following the terrorist attacks on the United States on September 11th. Journal of Personality and Social Psychology, 84, 365-376. doi:10.1037/ 0022-3514.84.2.365.

Gifford, E. V., Ritsher, J. B., McKellar, J. D., \& Moos, R. H. (2006). Acceptance and relationship context: A model of substance use disorder treatment outcome. Addiction (Abingdon, England), 101(8), 1167-1177. doi:10.1111/j.1360-0443.2006.01506.x.

Giordano, T. P., Guzman, D., Clark, R., Charlebois, E. D., \& Bangsberg, D. R. (2004). Measuring adherence to antiretroviral therapy in a diverse population using a visual analogue scale. HIV Clinical Trials, 5(2), 74-79. doi:10.1310/JFXH-G3X2EYM6-D6UG.

Gonzalez, J. S., Penedo, F. J., Antoni, M. H., Duran, R. E., McPherson-Baker, S., Ironson, G., et al. (2004). Social support, positive states of mind, and HIV treatment adherence in men and women living with HIV/AIDS. Health Psychology, 23(4), 413-418. doi:10.1037/0278-6133.23.4.413.

Gorbach, P. M., Drumright, L. N., Javanbakht, M., Pond, S. L., Woelk, C. H., Daar, E. S., et al. (2008). Antiretroviral drug resistance and risk behavior among recently HIV-infected men who have sex with men. Journal of Acquired Immune Deficiency Syndromes, 47(5), 639-643. doi:10.1097/QAI.0b013e3181684c3d.

Gordillo, V., del Amo, J., Soriano, V., \& Gonzalez-Lahoz, J. (1999). Sociodemographic and psychological variables influencing adherence to antiretroviral therapy. AIDS (London, England), 13(13), 1763-1769. doi:10.1097/00002030-199909100-00021.

Grov, C., Bimbi, D. S., Nanin, J. E., \& Parsons, J. T. (2006). Exploring racial and ethnic differences in recreational drug use among gay and bisexual men in New York City and Los Angeles. Journal of Drug Education, 36(2), 105-123. 
Halkitis, P. N., \& Jerome, R. C. (2008). A comparative analysis of methamphetamine use: Black gay and bisexual men in relation to men of other races. Addictive Behaviors, 33(1), 83-93. doi: 10.1016/j.addbeh.2007.07.015.

Halkitis, P. N., Moeller, R. W., Siconolfi, D. E., Jerome, R. C., Rogers, M., \& Schillinger, J. (2008). Methamphetamine and polysubstance use among gym-attending men who have sex with men in New York City. Annals of Behavioral Medicine, 35(1), 41-48.

Hayes, S. C., Wilson, K. G., Gifford, E. V., Follette, V. M., \& Strosahl, K. (1996). Experimental avoidance and behavioral disorders: A functional dimensional approach to diagnosis and treatment. Journal of Consulting and Clinical Psychology, 64(6), 1152-1168. doi:10.1037/0022-006X.64.6.1152.

Hinkin, C. H., Barclay, T. R., Castellon, S. A., Levine, A. J., Durvasula, R. S., Marion, S. D., et al. (2007). Drug use and medication adherence among HIV-1 infected individuals. AIDS and Behavior, 11, 185-194. doi:10.1007/s10461-006-9152-0.

Johnson, M. O., Catz, S. L., Remien, R. H., Rotheram-Borus, M. J., Morin, S. F., Charlebois, E., et al. (2003). Theory-guided, empirically supported avenues for intervention on HIV medication nonadherence: Findings from the Healthy Living Project. AIDS Patient Care and STDs, 17(12), 645-656. doi:10.1089/ 108729103771928708.

Johnson, M. O., Carrico, A. W., Chesney, M. A., \& Morin, S. F. (2008). Internalized heterosexism among HIV-positive gayidentified men: Implications for HIV prevention and care. Journal of Consulting and Clinical Psychology, 76, 829-839. doi:10.1037/0022-006X.76.5.829.

Kalichman, S. C., Rompa, D., \& Cage, M. (2000). Reliability and validity of self-reported CD4 lymphocyte count and viral load test results in people living with HIV/AIDS. International Journal of STD and AIDS, 11, 579-585. doi:10.1258/095646 2001916551.

Khantzian, E. J. (1997). The self-medication hypothesis of substance use disorders: A reconsideration and recent applications. Harvard Review of Psychiatry, 4(5), 231-244. doi:10.3109/1067 3229709030550.

Kosten, T. R., Markou, A., \& Koob, G. F. (1998). Depression and stimulant dependence: Neurobiology and pharmacotherapy. The Journal of Nervous and Mental Disease, 182(12), 413-421.

Littlewood, R. A., Vanable, P. A., Carey, M. P., \& Blair, D. C. (2008). The association of benefit finding to psychosocial and health behavior adaptation among HIV + men and women. Journal of Behavioral Medicine, . doi:10.1007/s10865-007-9142-3.

Mausbach, B. T., Semple, S. J., Strathdee, S. A., Zians, J., \& Patterson, T. L. (2007). Efficacy of a behavioral intervention for increasing safer sex behaviors in HIV-positive MSM methamphetamine users: Results from the EDGE study. Drug and Alcohol Dependence, 87(2-3), 249-257. doi:10.1016/j.drugalc dep.2006.08.026.

Morgenstern, J., Labouvie, E., McCrady, B. S., Kahler, C. W., \& Frey, R. M. (1997). Affiliation with alcoholics anonymous after treatment: A study of its therapeutic effects and mechanisms of action. Journal of Consulting and Clinical Psychology, 65(5), 768-777. doi:10.1037/0022-006X.65.5.768.

Morin, S. F., Myers, J. J., Shade, S. B., Koester, K., Maiorana, A., \& Rose, C. D. (2007). Predicting HIV transmission risk among HIVinfected patients seen in clinical settings. AIDS and Behavior, 11(5, Suppl), S6-S16. doi:10.1007/s10461-007-9253-4.

O'Cleirigh, C., Ironson, G., \& Smits, J. A. (2007). Does distress tolerance moderate the impact of major life events on psychosocial variables and behaviors important in the management of HIV? Behavior Therapy, 38(3), 314-323. doi:10.1016/ j.beth.2006.11.001.

Oyugi, J. H., Byakika-Tusiime, J., Charlebois, E. D., Kityo, C., Mugerwa, R., Mugyenyi, P., et al. (2004). Multiple validated measures of adherence indicate high levels of adherence to generic HIV antiretroviral therapy in a resource-limited setting. Journal of Acquired Immune Deficiency Syndromes, 36(5), 1100-1102. doi:10.1097/00126334-200408150-00014.

Semple, S. J., Patterson, T. L., \& Grant, I. (2002). Motivations associated with methamphetamine use among HIV+ men who have sex with men. Journal of Substance Abuse Treatment, 22(3), 149-156. doi:10.1016/S0740-5472(02)00223-4.

Simoni, J. M., Kurth, A. E., Pearson, C. R., Pantalone, D. W., Merrill, J. O., \& Frick, P. A. (2006). Self-report measures of antiretroviral therapy adherence: A review with recommendations for HIV research and clinical management. AIDS and Behavior, 10(3), 227-245. doi:10.1007/s10461-006-9078-6.

Sledjeski, E. M., Delahanty, D. L., \& Bogart, L. M. (2005). Incidence and impact of posttraumatic stress disorder and comorbid depression on adherence to HAART and CD4+ counts in people living with HIV. AIDS Patient Care and STDs, 19(11), 728-736. doi:10.1089/apc.2005.19.728.

Starace, F., Ammassari, A., Trotta, M. P., Murri, R., De Longis, P., Izzo, C., et al. (2002). Depression is a risk factor for suboptimal adherence to highly active antiretroviral therapy. Journal of Acquired Immune Deficiency Syndromes, 31(Suppl 3), S136S139.

Sundin, E. C., \& Horowitz, M. J. (2002). Impact of event scale: Psychometric properties. The British Journal of Psychiatry, 180, 205-209. doi:10.1192/bjp.180.3.205.

Sundin, E. C., \& Horowitz, M. J. (2003). Horowitz's impact of event scale evaluation of 20 years of use. Psychosomatic Medicine, 65(5), 870-876. doi:10.1097/01.PSY.0000084835.46074.F0.

Tice, D. M., Baumeister, R. F., Shmueli, D., \& Muraven, M. (2007). Restoring the self: Positive affect helps improve self-regulation following ego depletion. Journal of Experimental Social Psychology, 43, 379-384. doi:10.1016/j.jesp.2006.05.007.

Vranceanu, A. M., Safren, S. A., Lu, M., Coady, W. M., Skolnik, P. R., Rogers, W. H., et al. (2008). The relationship of posttraumatic stress disorder and depression to antiretroviral medication adherence in persons with HIV. AIDS Patient Care and STDs, 22, 313-321. doi:10.1089/apc.2007.0069.

Watson, D., Clark, L. A., \& Tellegen, A. (1988). Development and validation of brief measures of positive and negative affect: The PANAS scales. Journal of Personality and Social Psychology, 54(6), 1063-1070. doi:10.1037/0022-3514.54.6.1063.

Weaver, K. E., Llabre, M. M., Duran, R. E., Antoni, M. H., Ironson, G., Penedo, F. J., et al. (2005). A stress and coping model of medication adherence and viral load in HIV-positive men and women on highly active antiretroviral therapy (HAART). Health Psychology, 24(4), 385-392. doi:10.1037/0278-6133.24.4.385.

Wills, T. A., Sandy, J. M., Shinar, O., \& Yaeger, A. (1999). Contributions of positive and negative affect to adolescent substance use: Test of a bidimensional model in a longitudinal study. Psychology of Addictive Behaviors, 13(4), 327-338. doi: 10.1037/0893-164X.13.4.327.

Witkiewitz, K., \& Marlatt, G. A. (2004). Relapse prevention for alcohol and drug problems: That was zen, this is tao. The American Psychologist, 59(4), 224-235. doi:10.1037/0003-06 6X.59.4.224. 